\title{
Alterations of morphology of lymphoid organs and peripheral blood indicators under the influence of gold nanoparticles in rats
}

\author{
Alla B. Bucharskaya*,\|, Svetlana S. Pakhomy*, Olga V. Zlobina*, \\ Galina N. Maslyakova*, Olga V. Matveeva*, Irina O. Bugaeva*, Nikita A. Navolokin*, \\ Boris N. Khlebtsov $^{\dagger}$, Vladimir A. Bogatyrev ${ }^{\dagger}$, Nikolai G. Khlebtsov ${ }^{\dagger}$, \\ and Valery V. Tuchin \\ *Saratov State Medical University \\ 112, B. Kazach'ya str., Saratov 410012, Russia \\ ${ }^{\dagger}$ Institute of Biochemistry and Physiology of Plants \\ and Microorganisms RAS \\ 13, Entuziastov Prospekt., Saratov 410049, Russia \\ ${ }^{\star}$ Saratov State University 83 , \\ Astrakhanskaya str., Saratov 410012, Russia \\ ${ }^{\S}$ Institute of Precise Mechanics and Control \\ of Russian Academy of Sciences \\ 24, Rabochaya str., Saratov 410028, Russia \\ IInterdisciplinary Laboratory of Biophotonics \\ Tomsk State University \\ 36, Lenina str., Tomsk 634050, Russia \\ "|allaalla_72@mail.ru
}

Received 23 October 2015

Accepted 31 December 2015

Published 30 January 2016

\begin{abstract}
At present, gold nanoparticles (GNPs) are widely used in biomedical applications such as cancer diagnostics and therapy. Accordingly, the potential toxicity hazards of these nanomaterials and human safety concerns are gaining significant attention. Here, we report the effects of prolonged peroral administration of GNPs with different sizes $(2,15$ and $50 \mathrm{~nm})$ on morphological changes in lymphoid organs and indicators of peripheral blood of laboratory animals. The experiment was conducted on 24 white mongrel male rats weighing 180-220 g, gold nanospheres sizes 2, 15 and $50 \mathrm{~nm}$ were administered orally for 15 days at a dosage of $190 \mu \mathrm{g} / \mathrm{kg}$ of animal body weight. The GNPs were conjugated with polyethylene glycol to increase their biocompatibility and bioavailability. The size-dependent decrease of the number of neutrophils and lymphocytes was
\end{abstract}

\|Corresponding author.

This is an Open Access article published by World Scientific Publishing Company. It is distributed under the terms of the Creative Commons Attribution 4.0 (CC-BY) License. Further distribution of this work is permitted, provided the original work is properly cited. 


\section{A. B. Bucharskaya et al.}

noted in the study of peripheral blood, especially pronounced after administration of GNPs with size of $50 \mathrm{~nm}$. The stimulation of myelocytic germ of hematopoiesis was recorded at morphological study of the bone marrow. The signs of strengthening of the processes of differentiation and maturation of cellular elements were found in lymph nodes, which were showed as the increasing number of immunoblasts and large lymphocytes. The quantitative changes of cellular component morphology of lymphoid organs due to activation of migration, proliferation and differentiation of immune cells indicate the presence of immunostimulation effect of GNPs.

Keywords: Gold nanoparticles; lymphoid organs; morphological changes; bone marrow examination.

\section{Introduction}

The rapid development of nanotechnologies led to the emergence of new nanomaterials in the electronics, food industry, pharmaceutics, cosmetics, paints and surface coatings. ${ }^{1}$

Since gold nanoparticles (GNPs) have unique features, the development of a variety of medical applications has been possible. The using of GNPs for photothermal sensitization of tumors to improve the efficiency and selectivity of laser treatment of cancer is well known. ${ }^{2}$ Such applications of GNPs require that extensive research should be conducted to investigate the safety of nanoparticles for life in general and man in particular. Currently, most of in vivo data obtained after intravenous administration of the nanoparticles, whereas data about intraperitoneal, respiratory and oral administration is rather limited.

The influence of size, solubility and surface modification on the biocompatibility of nanoparticles and their use in biological applications is well known. ${ }^{3}$ In 2001, Hillyer and Albrecht ${ }^{4}$ first noted size-dependent nature of the gold biodistribution upon oral administration, when 4, 10, 28 and $58 \mathrm{~nm}$ GNPs were administered (in a concentration of $200 \mathrm{mg} / \mathrm{ml}$ ) for seven days with drinking water. Four nanometer particles pass through the gastrointestinal tract, absorbed by enterocytes in the villi and have been degraded and then are distributed through the bloodstream to organs. Penetration through gastrointestinal tract blood decreased with increasing of particle size.

In our work, ${ }^{5}$ the particle size effects on the distribution of $15 \mathrm{~nm}$ and $50 \mathrm{~nm}$ PEG-coated colloidal gold (CG) particles and $160 \mathrm{~nm}$ silica/gold nanoshells (NSs) after intravenous administration (about $0.3 \mathrm{mg} \mathrm{Au} / \mathrm{kg}$ ) were described in rats. In $24 \mathrm{~h}$ after injection, the accumulation of gold in different organs and blood was determined by atomic absorption spectroscopy. In accordance with the published reports,,${ }^{6,7}$ we observed $15 \mathrm{~nm}$ particles in all organs with rather smooth distribution over liver, spleen and blood. By contrast, the larger NSs were accumulated mainly in the liver and spleen.

In work of Zhang et al. ${ }^{8}$ an animal toxicity study of $13.5 \mathrm{~nm}$ GNPs in mice was presented. Animal survival, weight, hematology, morphology and organ index are characterized at different concentrations $(137.5-2200 \mu \mathrm{g} / \mathrm{kg})$ over $14-28$ days. The results show that low concentrations of GNPs do not cause an obvious decrease in body weight or appreciable toxicity. High concentrations of GNPs induced decrease in body weight, $\mathrm{RBC}$ count (the number of red blood cells (RBCs) per volume of blood), and hematocrit. It was also found that GNPs administered orally caused significant decrease in body weight, spleen index and RBC count. Among three administration routes, the oral and intraperitoneal routes showed the highest toxicity, and the tail vein injection showed the lowest toxicity.

Thus, GNPs are a promising carrier for immune therapies because, like other nanoparticles, they easily accumulate in the immune system organs. ${ }^{9-11}$

Despite numerous studies focused on the biodistribution and toxicity of GNPs, their effects on the immune system were insufficiently studied. In pioneering review of $\mathrm{Pacheco}^{12}$ the effect of CG on the nonspecific immune response was described. It was noted that in $2 \mathrm{~h}$ after intravenous administration of $5 \mathrm{ml}$ of $\mathrm{CG}$ to rabbits the total leukocyte count in $1 \mathrm{ml}$ blood increased (from 9900 to 19,800) with small reduction of mononuclear forms (from 5200 to 4900) and a significant increase of segmented neutrophils (from 4700 to 14,900).

Chen et al. ${ }^{10}$ studied in vivo toxicity of naked GNPs ranging from 3 to $100 \mathrm{~nm}$ in mice at intraperitoneal administration in dosage of $8 \mathrm{mg} / \mathrm{kg} /$ week and only GNPs ranging from 8 to $37 \mathrm{~nm}$ 
induced severe sickness in mice. Pathological examination of the major organs of the mice in the diseased groups indicated an increase of Kupffer cells in the liver, loss of structural integrity in the lungs, and diffusion of white pulp in the spleen. The pathological abnormality was associated with the presence of GNPs at the diseased sites, which were verified by ex vivo Coherent anti-Stoke Raman scattering microscopy. Modifying the surface of the GNPs by incorporating immunogenic peptides ameliorated their toxicity. This reduction in the toxicity is associated with an increase in the ability to induce antibody response.

Zhang et al. ${ }^{11}$ studied in vivo toxicity of $5,10,30$ and $60 \mathrm{~nm}$ PEG-coated GNPs in mice at intraperitoneal administration in dosage of $4000 \mu \mathrm{g} / \mathrm{kg}$ over 28 days. The increase in spleen index and thymus index shows that the immune system can be affected by these small nanoparticles. Transmission electron microscopic observations showed that the 5, 10, 30 and $60 \mathrm{~nm}$ particles located in the blood and bone marrow cells, and that the $5 \mathrm{~nm}$ and $60 \mathrm{~nm}$ particles aggregated preferentially in the blood cells. The $10 \mathrm{~nm}$ GNPs induced an increase in white blood cell (WBC) concentration, while the $5 \mathrm{~nm}$ and $30 \mathrm{~nm}$ particles induced a decrease of concentration of WBCs and RBCs.

Furthermore, it is known that the GNPs and their conjugates with antigens stimulate respiratory activity of reticuloendothelial system cells and the activity of mitochondrial enzymes of macrophages. ${ }^{13}$ This is probably one of the reasons for the adjuvant properties of CG.

Additionally, contradictory data exist on the immunological effects of GNPs once internalized by immune system cells. GNPs were shown to induce either pro-inflammatory ${ }^{14}$ or anti-inflammatory effects, ${ }^{15,16}$ depending on their size, conjugation and hydrophobicity. ${ }^{17}$

For instance, Yen et al. ${ }^{14}$ have shown that GNPs in the 2 to $40 \mathrm{~nm}$ size range can induce macrophage expression of inflammatory genes for TNF $\alpha$ and IL-6 in vitro. Sumbayev et al. in turn, show that AuNPs can suppress IL- $1 \beta$ dependent inflammatory responses in vitro and in vivo in a size-dependent manner. ${ }^{18}$

The in vitro study of dendritic cells, a major actor of both innate and acquired immune responses, shown no cytotoxicity of GNPs even at their high concentration. ${ }^{15}$

The electron microscopy shown ${ }^{19}$ macrophage activation at penetration of GNPs conjugated with the peptides in their cytoplasm. It was found that after the interaction of conjugates with TLR-4 receptors of macrophages nanoparticles penetrated into cells, which was accompanied by the release of inflammatory cytokines - TNF, interleukins $1 \beta$ and 6 , and inhibition of macrophage proliferation ability. After administration of GNPs the number of macrophages was decreased and their size increased. ${ }^{14}$ The levels of interleukins $1 \beta$ and 6 and TNF went down. Finally, Tsai et al. ${ }^{16}$ have demonstrated that treatment with particles of 4 to $45 \mathrm{~nm}$ can inhibit macrophage toll like receptor 9 responding to CpG.

Thus, further study of immunotoxic or immunostimulation effects of GNPs are necessary for better understanding the character of GNP interactions with the immune system. The aim of the work was a comprehensive in vivo study of GNPs of different sizes on the morphofunctional state of immunogenesis and the peripheral blood status of laboratory animals.

\section{Methods}

Gold nanoparticles with average diameters of 2,15 and $50 \mathrm{~nm}$ and a mass-volume concentration of $57 \mu \mathrm{g} / \mathrm{mL}$ were synthesized as previously described. ${ }^{20}$ In particular, 15 and $50 \mathrm{~nm}$ GNPs were synthesized by the Frens method, ${ }^{21}$ and the smallest $2 \mathrm{~nm}$ GNPs were obtained by the Duff method. ${ }^{22}$ The corresponding particle number concentrations are $8.8 \times 10^{13}, 1.7 \times 10^{12}$ and $4.5 \times 10^{10}$ particles/ $\mathrm{mL}$, respectively. The average size of the GNPs was determined from electron microscopic images obtained using a Libra-120 microscope (Carl Zeiss, Jena, Germany) in Centre of Collective Use of Institute of Biochemistry and Physiology of Plants and Microorganisms RAS. For increased biocompatibility, 15 and $50 \mathrm{~nm}$ GNPs were conjugated with thiolated polyethylene glycol mPEG-SH $(\mathrm{Mw}=5000$, Nektar Therapeutics) as described previously. ${ }^{23}$ The smallest $2 \mathrm{~nm}$ GNPs were used as prepared. The GNP-mPEG conjugates were formed by the covalent binding of thiol groups to the surface of GNPs. The resulting conjugates were washed twice by centrifugation to remove excess reaction products and resuspended in $0.9 \%$ sodium chloride solution.

The experimental study was conducted in Center of Collective Use of Saratov State Medical University (Russia) according to the University's Animal Ethics Committee (Russia) and the relevant 
national agency regulating experiments in animals. The international guiding principles for biomedical research involving animals of the Council for the International Organization of Medical Sciences and International Council for Laboratory Animal Science (CIOMS\&ICLAS, 2012) were followed during the animal experiments.

The study for 24 healthy adult albino male rats weighing $180-220 \mathrm{~g}$ was performed. The rats were kept under a constant $12 \mathrm{~h}$ light-dark cycle at $22^{\circ} \mathrm{C}-$ $25^{\circ} \mathrm{C}$ with standard chow and water provided ad libitum. The study of morphological changes in the lymphoid organs was conducted after a 15 days oral administration of GNPs of different sizes. The animals were randomly divided into four groups: Three experimental groups and a control group (six animals in each group). Rats in experimental groups were orally administered by $1 \mathrm{ml}$ of GNPs once a day for 15 days at a dosage of $190 \mu \mathrm{g} / \mathrm{kg}$ of body weight as follows: First group $\sim 1-3 \mathrm{~nm}$ GNPs, second group $\sim 15 \mathrm{~nm}$ GNPs and third group $\sim 50 \mathrm{~nm}$ GNPs. Oral gavage was used for repeated oral administration. Sedation prior to gavage is not necessary. ${ }^{24}$ Rats in control group were administered orally once a day for 15 days $1 \mathrm{ml}$ of saline. The withdraw of animals and sampling were performed in $24 \mathrm{~h}$ after the last administration. The anesthesia with Zoletil 50 (Virbac, France) in a dose of $0.05 \mathrm{mg} / \mathrm{kg}$ was applied before sacrificing of animals.

Bone marrow sampling was conducted by the standard procedure from the femur. For morphological examination, bone marrow smears were stained by May-Grunwald. Morphological analysis of smears was performed under high magnification $(\times 1000)$ with differential counts of 200 cells. Blood sampling was performed using special tubes for hematology after animal decapitation. Standard hematologic analysis was performed on the hematology analyzer Micros-60 ABX.

For morphological examination, the organ specimens of rats (spleen, lymph nodes) were fixed in $10 \%$ formalin solution, then subjected to a standard alcohol and acetone wiring and embedded in paraffin. After sample dewaxing, 5-7 micron thick sections were stained with hematoxylin and eosin. Morphometric analysis of the histological preparations was conducted using the digital image analysis system Mikrovizor medical $\mu$ Vizo-101 (LOMO, Russia).

Counting of cell elements of mesenteric lymph nodes were carried out in the various functional areas of the lymph node by the standard method with magnification $\times 100, \times 400, \times 1000$ using morphometric software image analyzer in 10 fields of view on the conventional unit area $\left(6400 \mu \mathrm{m}^{2}\right)$. Digital camera SCOPETEK DCM (Hangzhou Scopetek Opto-Electric Co., China) used to capture histopathological images. The classification of analyzed cell elements was conducted according to required criteria and reporting. Analysis of results was displayed in the form of histograms, charts and tables.

The Perls reaction ${ }^{23}$ was used for the differential diagnosis of hemosiderin and GNP clusters. The reaction with methyl green pyronin by Brachet ${ }^{23}$ was used to identify and count the number of plasma cells in the lymph nodes.

The dark-field microscopy was used to identify clusters of GNPs in samples using a Leica DM 2500 microscope with a special attachment that permits lateral illumination at magnification of $\times 400$.

The experimental data were analyzed using a statistical software package STATISTICA 10.0 (StatSoft Inc., USA). Preliminary statistical data processing was performed by the KolmogorovSmirnov test to verify compliance of distribution forms to normal, and the equality of the population variance was determined using the Fisher $F$-test. The null hypothesis was rejected when $p<0.05$. The arithmetic mean $(\mathrm{M})$ and the error of the arithmetic mean $(\mathrm{m})$ were calculated for each index. The differences between the samples were assessed using Student's $t$-test.

\section{Results}

At the analysis of peripheral blood indicators of laboratory animals it was found that the decrease in the number of leukocytes was observed only in groups with $15 \mathrm{~nm}$ and $50 \mathrm{~nm}$ GNPs administration (Table 1). The decrease of WBC count of more than two-fold $(p<0.05)$ was noted in the group of animals with $15 \mathrm{~nm}$ GNPs administration, mainly due to decrease of lymphocyte number $(p<0.05)$. The significant decrease in the number of WBCs $(p<0.05)$ was found in group with $50 \mathrm{~nm}$ GNPs administration due to reducing of the number of lymphocytes $(p<0.05)$ and monocytes $(p<0.05)$.

After administration of $2 \mathrm{~nm}$ and $15 \mathrm{~nm}$ GNPs there was a significant decrease of mean corpuscular volume (MCV) and an increase of mean corpuscular hemoglobin concentration (MCHC) of hemoglobin. 
Table 1. Peripheral blood indicators of laboratory animals after GNP administration.

\begin{tabular}{lcccc}
\hline & & \multicolumn{2}{c}{ Experimental groups with GNPs administration } \\
\cline { 3 - 5 } The indicators of blood & Control group & $2 \mathrm{~nm}$ & $15 \mathrm{~nm}$ & $50 \mathrm{~nm}$ \\
\hline $\mathrm{WBC}\left(\times 10^{9} / \mathrm{l}\right)$ & $12.4 \pm 3.9$ & $13.0 \pm 8.6$ & $5.2 \pm 3.5^{*}$ & $3.8 \pm 0.4^{*}$ \\
$\mathrm{LYM}\left(\times 10^{9} / \mathrm{l}\right)$ & $9.6 \pm 2.2$ & $8.8 \pm 2.9$ & $3.5 \pm 2.4^{*}$ & $2.7 \pm 0.5^{*}$ \\
$\operatorname{MON}\left(\times 10^{9} / \mathrm{l}\right)$ & $1.7 \pm 0.5$ & $1.7 \pm 0.5$ & $0.8 \pm 0.6$ & $0.5 \pm 0.1^{*}$ \\
$\mathrm{GRA}\left(\times 10^{9} / \mathrm{l}\right)$ & $1.0 \pm 0.4$ & $2.5 \pm 1.2$ & $0.9 \pm 0.7$ & $0.6 \pm 0.1$ \\
$\mathrm{RBC}\left(\times 10^{12} / \mathrm{l}\right)$ & $6.9 \pm 1.2$ & $6.0 \pm 1.2$ & $4.6 \pm 3.2$ & $6.4 \pm 0.4$ \\
$\mathrm{HGB}(\mathrm{g} / \mathrm{l})$ & $108 \pm 12$ & $109 \pm 23$ & $116 \pm 22$ & $111 \pm 10$ \\
$\mathrm{HCT} \%$ & $34.1 \pm 4.5$ & $26.3 \pm 5.2$ & $28.8 \pm 4.6$ & $28.2 \pm 2.2$ \\
$\operatorname{MCV}\left(\mu \mathrm{m}^{3}\right)$ & $50.5 \pm 3.5$ & $44.0 \pm 0.8^{*}$ & $43.7 \pm 1.5^{*}$ & $44.5 \pm 1.3^{*}$ \\
$\operatorname{MCHC} \%$ & $35.6 \pm 3.2$ & $41.3 \pm 1.5^{*}$ & $40.3 \pm 2.1^{*}$ & $39.2 \pm 1.6$ \\
$\operatorname{PLT}\left(\mathrm{x} 10^{9} / \mathrm{l}\right)$ & $510.5 \pm 91.4$ & $457.2 \pm 88.3$ & $460.5 \pm 162.6$ & $366.2 \pm 87.9$ \\
\hline
\end{tabular}

Note: ${ }^{*}$ — The significance of differences with control group.

In the group of animals with $50 \mathrm{~nm}$ GNPs the decrease of MCHC was also noted $(p<0.05)$.

The signs of stimulation of leukocyte hemopoietic germ were observed at morphological analysis of the bone marrow after administration of all kinds of GNPs - the increase of the number of myelocytes, metamyelocytes and stab leukocytes was observed in all groups (Table 2). At the same time, the decrease of amount of the mature forms (segmented neutrophils, Fig. 1) was noted after administration of $15 \mathrm{~nm}$ and $50 \mathrm{~nm}$ GNPs, which causes the significant reduction of leukocytic-erythroblastic ratio.

At morphometric analysis, the differences of cell populations from different functional zones of mesenteric lymph nodes were not revealed in group with 1-3 nm GNPs administration compared with control group (Table 3).

At histological examination, the increase of secondary follicles with germinal centers were found in zone of lymph follicles after $15 \mathrm{~nm}$ and $50 \mathrm{~nm}$ GNPs administration, which indirectly indicates the activation of lymphopoiesis. The increase of small lymphocytes $(p<0.05)$; medium lymphocytes $(p<0.05)$; and immunoblasts $(p<0.05)$ were observed after $15 \mathrm{~nm}$ and $50 \mathrm{~nm}$ GNPs administration. The increase of number of mitotic figures was found in zone of lymph follicles at administration of $15 \mathrm{~nm}(p<0.05)$ and $50 \mathrm{~nm}$ GNPs $(p<0.05)$.

Table 2. The morphological changes in bone marrow.

\begin{tabular}{lcccc}
\hline & & \multicolumn{2}{c}{ Experimental groups with GNP administration } \\
\cline { 3 - 5 } The indicators of bone marrow $(\%)^{1}$ & Control group & $2 \mathrm{~nm}$ & $15 \mathrm{~nm}$ & $50 \mathrm{~nm}$ \\
\hline Myeloblasts & $1.0 \pm 0.7$ & $1.3 \pm 0.7$ & $0.8 \pm 0.5$ & $1.7 \pm 0.6$ \\
Neutrophil myelocytes & $1.2 \pm 0.3$ & $6.0 \pm 2.1$ & $6.7 \pm 1.5^{*}$ & $7.0 \pm 1.7^{*}$ \\
Neutrophil metamyelocytes & $3.0 \pm 0.7^{*}$ & $13.3 \pm 2.9^{*}$ & $10.7 \pm 2.4^{*}$ & $11.3 \pm 3.3^{*}$ \\
Neutrophil stab leukocytes & $7.5 \pm 1.8$ & $17.0 \pm 1.0^{*}$ & $17.5 \pm 1.7^{*}$ & $13.0 \pm 1.7^{*}$ \\
Neutrophil segments & $32.8 \pm 8.3$ & $22.0 \pm 6.1$ & $23.2 \pm 3.9$ & $23.0 \pm 2.6$ \\
Eosinophils & $1.7 \pm 0.7$ & $1.7 \pm 0.6$ & $1.3 \pm 0.9$ & $0.7 \pm 0.6$ \\
Basophils & $0.3 \pm 0.3$ & $0.8 \pm 0.3$ & $0.3 \pm 0.2$ & $0.3 \pm 0.3$ \\
Monocytes & $0.7 \pm 0.1$ & $2.0 \pm 1.7$ & $1.8 \pm 1.7$ & $1.3 \pm 1.2$ \\
Lymphocytes & $16.0 \pm 1.2$ & $14.3 \pm 3.1$ & $16.5 \pm 4.0$ & $14.3 \pm 3.2$ \\
Erythroblasts & 0 & 0 & $0.5 \pm 1.0$ & $0.3 \pm 0.6$ \\
Basophilic normocytes & $1.0 \pm 0.1$ & $2.0 \pm 0.0$ & $1.8 \pm 1.3$ & $2.7 \pm 0.6$ \\
Polychromatic normocytes & $12.0 \pm 0.2$ & $17.7 \pm 4.2$ & $13.5 \pm 6.4$ & $20.0 \pm 4.3$ \\
Oxyphilic normocytes & $3.0 \pm 0.3$ & $2.7 \pm 1.15$ & $3.3 \pm 0.5$ & $4.7 \pm 1.5$ \\
Leukocytic-erythroblastic ratio & $2.6 \pm 0.2$ & $1.7 \pm 0.7$ & $2.1 \pm 0.4^{*}$ & $1.2 \pm 0.3^{*}$ \\
\hline
\end{tabular}

Notes: ${ }^{1}$ The individual cell types were counted within 200 of bone marrow cells.

* - The significance of differences with control group. 
Table 3. The morphological changes in mesenteric lymph nodes.

\begin{tabular}{|c|c|c|c|c|c|}
\hline \multirow[b]{2}{*}{ Zones of lymphatic nodes } & \multirow{2}{*}{$\begin{array}{l}\text { The number of cells } \\
\text { (within area of } 6400 \mu \mathrm{m}^{2} \text { ) }\end{array}$} & \multirow[b]{2}{*}{ Control group } & \multicolumn{3}{|c|}{ Experimental groups with GNPs administration } \\
\hline & & & $2 \mathrm{~nm}$ & $15 \mathrm{~nm}$ & $50 \mathrm{~nm}$ \\
\hline \multirow[t]{7}{*}{ Lymph follicles } & Small lymphocytes & $64.2 \pm 3.1$ & $62.3 \pm 4.6$ & $71.2 \pm 3.4^{*}$ & $83.3 \pm 4.7^{*}$ \\
\hline & Middle lymphocytes & $18.2 \pm 1.4$ & $16.6 \pm 2.2$ & $30.1 \pm 2.1^{*}$ & $35.3 \pm 3.0^{*}$ \\
\hline & Large lymphocytes & 0 & $0.5 \pm 0.1$ & $2.2 \pm 0.7$ & $9.6 \pm 1.2$ \\
\hline & Immunoblasts & $2.5 \pm 0.3$ & $2.9 \pm 0.2$ & $4.8 \pm 0.3^{*}$ & $10.4 \pm 1.3^{*}$ \\
\hline & Plasmocytes & 0 & $0.1 \pm 0.1$ & 0 & $0.4 \pm 0.5$ \\
\hline & Mastocytes & 0 & 0 & $0.6 \pm 0.2$ & $0.8 \pm 0.1$ \\
\hline & Mitotic figures & $0.2 \pm 0.1$ & $0.7 \pm 0.1$ & $4.0 \pm 0.3^{*}$ & $4.6 \pm 0.7^{*}$ \\
\hline \multirow[t]{7}{*}{ Paracortical zone } & Small lymphocytes & $60.1 \pm 3.2$ & $61.2 \pm 5.4$ & $66.2 \pm 2.1^{*}$ & $72.4 \pm 4.1^{*}$ \\
\hline & Middle lymphocytes & $12.1 \pm 1.1$ & $14.3 \pm 1.8$ & $19.1 \pm 1.8$ & $26.6 \pm 2.8$ \\
\hline & Large lymphocytes & $0.8 \pm 0.1$ & $0.7 \pm 0.1$ & $1.2 \pm 0.3$ & $1.2 \pm 0.1$ \\
\hline & Immunoblasts & 0 & 0 & $0.7 \pm 0.1^{*}$ & $2.9 \pm 0.1^{*}$ \\
\hline & Plasmocytes & $0.7 \pm 0.1$ & 0 & $1.2 \pm 0.1$ & $1.8 \pm 0.4$ \\
\hline & Mastocytes & 0 & 0 & $0.3 \pm 0.01$ & $2.0 \pm 0.6$ \\
\hline & Mitotic figures & $0.8 \pm 0.16$ & $0.9 \pm 0.2$ & $1.2 \pm 0.1$ & $2.1 \pm 0.16$ \\
\hline \multirow[t]{7}{*}{ Medulla cords } & Small lymphocytes & $20.2 \pm 1.3$ & $18.3 \pm 1.0$ & $12.6 \pm 0.1$ & $20.8 \pm 0.6$ \\
\hline & Middle lymphocytes & $10.2 \pm 1.7$ & $10.4 \pm 1.0$ & $12.7 \pm 1.1$ & $22.3 \pm 1.2$ \\
\hline & Large lymphocytes & $10.2 \pm 1.7$ & $0.3 \pm 0.1$ & $0.5 \pm 0.1$ & $3.6 \pm 1.2$ \\
\hline & Immunoblasts & $2.3 \pm 0.3$ & $2.0 \pm 0.3$ & $3.5 \pm 0.4$ & $5.2 \pm 1.0$ \\
\hline & Plasmocytes & $15.3 \pm 1.6$ & $17.9 \pm 1.2$ & $26.4 \pm 3.4^{*}$ & $38.4 \pm 3.4^{*}$ \\
\hline & Mastocytes & $0.3 \pm 0.01$ & $0.1 \pm 0.07$ & $1.4 \pm 0.1$ & $3.4 \pm 0.5$ \\
\hline & Mitotic figures & $0.7 \pm 0.1$ & $0.9 \pm 0.2$ & $3.5 \pm 0.1$ & $4.2 \pm 0.2$ \\
\hline
\end{tabular}

Note: * The significance of differences with control group.

The increase of small lymphocytes $(p<0.05)$ and immunoblasts $(p<0.05)$ were found in the paracortical zone of mesenteric lymph nodes after $15 \mathrm{~nm}$ and $50 \mathrm{~nm}$ GNPs administration (Fig. 2).

The medulla cords are composed of plasma cells producing antibodies, their precursors, macrophages and $\mathrm{T}$ helper cells. The most prominent cell in the cord is the precursor to plasma cells or immunoblasts that came from the germinal centers

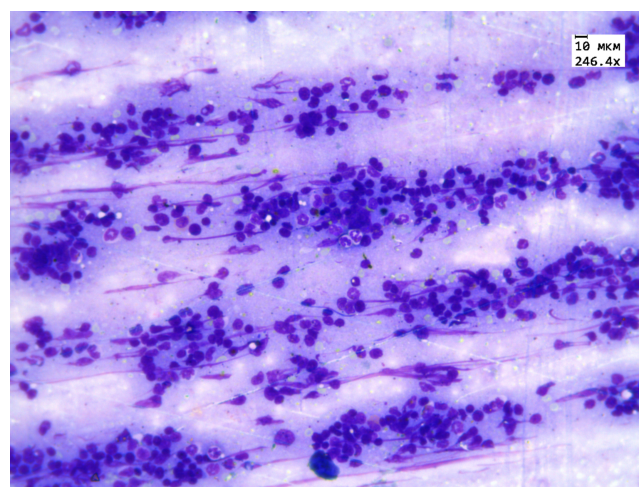

(a) of the lymphoid follicles in the cortex of the node. The increase of the number of plasmocytes in the area of medulla cords of mesenteric lymph nodes was revealed after administration of $15 \mathrm{~nm}$ and $50 \mathrm{~nm}$ GNPs.

Thus, the morphokinetics of cellular elements in mesenteric lymph nodes at GNPs administration was characterized by activation of lymphopoiesis and had size-dependent nature. The most pronounced

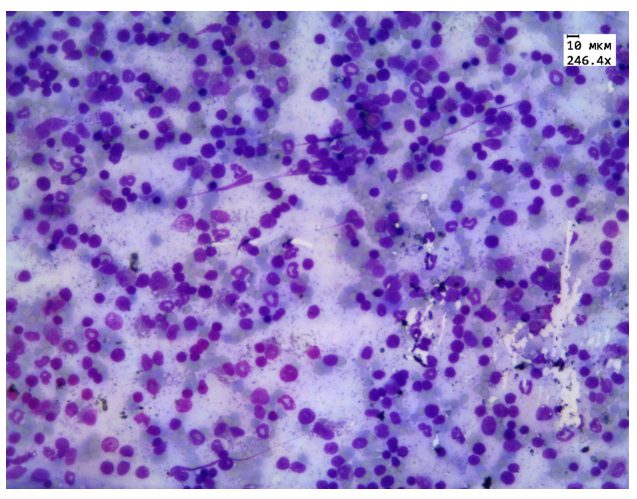

(b)

Fig. 1. Bone marrow smear, May-Grunwald staining, 246.4×: control group (a); group at 50 nm GNPs administration (b); the increase in the number of myelocytes, metamyelocytes and stab leukocytes at $50 \mathrm{~nm}$ GNP administration is seen. 


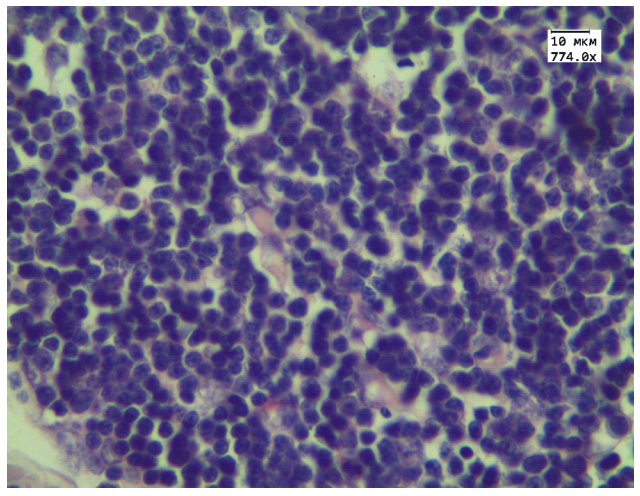

(a)

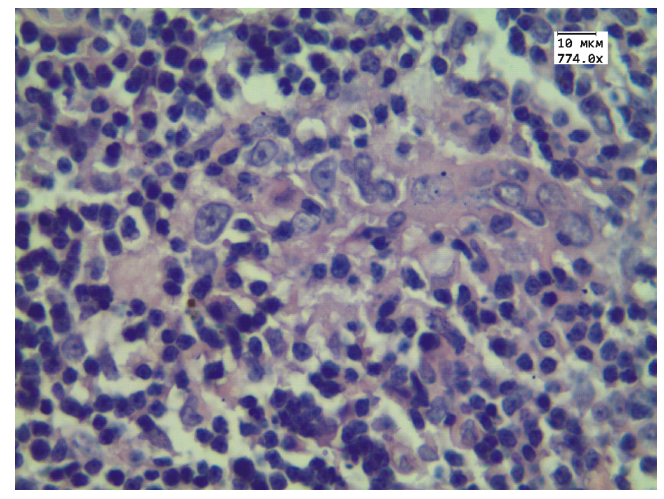

(b)

Fig. 2. Mesenteric lymph node histology, cortex, H\&E staining, 774.0×: Control group, primary follicle (a); experimental group under $50 \mathrm{~nm}$ GNP administration, germinal center of secondary follicle (b).

changes occurred at administration of $15 \mathrm{~nm}$ and $50 \mathrm{~nm}$ particles.

The signs of circulatory disorders of varying severity and activation of proliferative processes was observed in the spleen at GNPs administration. Insufficient blood supply was noted in $75 \%$ cases in the group of animals with $15 \mathrm{~nm}$ GNPs administration. In all groups of animals, the lymphoid follicles of spleen contain bright germinal centers represented by large blast cells, which indicate activation of proliferative processes (Fig. 3). According to the morphometric analysis, the average size of germinal centers at administration of $2 \mathrm{~nm}$ and $50 \mathrm{~nm}$ GNPs were $438 \pm 20 \mu \mathrm{m}^{2}$ and $456 \pm 130 \mu \mathrm{m}^{2}$, respectively, and at administration of $15 \mathrm{~nm}$ GNPs $-365 \pm 180 \mu \mathrm{m}^{2}$ (control values of $0.201 \pm 0.01 \mathrm{~mm}^{2} ; p<0.05$ ).

\section{Discussion}

The minor toxic effects of $15 \mathrm{~nm}$ and $50 \mathrm{~nm}$ GNPs found in our work are consistent with the experimental data by Hillyert and Albrecht, ${ }^{4}$ wherein the biodistribution was investigated for GNPs with diameters of 4, 10, 28 and $58 \mathrm{~nm}$ at peroral administration to mice for seven days with GNP suspension at a concentration of $200 \mu \mathrm{g} / \mathrm{mL}$.

It was found that $4 \mathrm{~nm}$ GNPs can be absorbed through the digestive tract, and redistributed by internal organs in significant quantities. By increasing the particle size, the permeability of the digestive tract for GNPs was significantly reduced.

Findings of significant toxic effect of GNPs in studies $^{8,10}$ were probably associated with the significantly higher doses and absence of coating of GNPs. In Ref. 8,

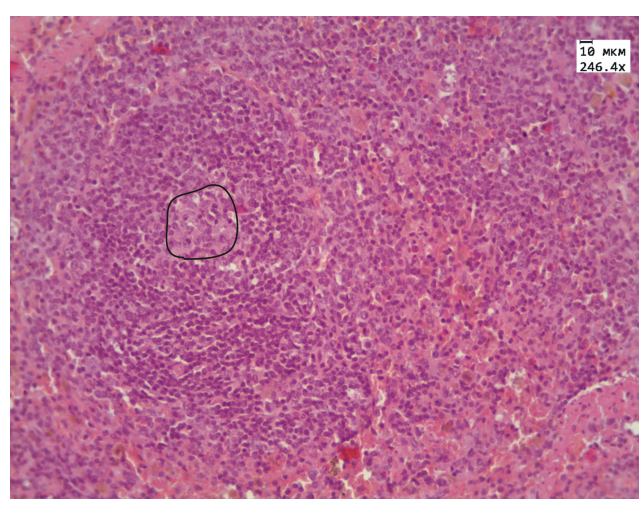

(a)

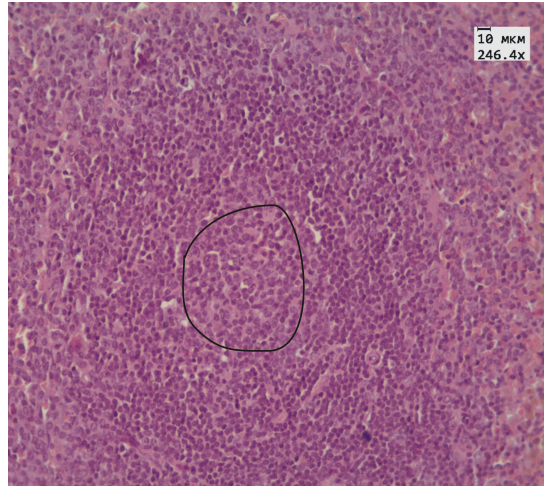

(b)

Fig. 3. Spleen histology, H\&E staining, 246.4×: control group (a), group with $15 \mathrm{~nm}$ GNP administration, the selected area indicates bright germinal center in the follicle (b). 


\section{A. B. Bucharskaya et al.}

after 14-28 days of oral administration obvious effects on organ index in mice have been observed only at high concentration of naked $13.5 \mathrm{~nm}$ GNPs. In Ref. 10, only GNPs ranging from 8 to $37 \mathrm{~nm}$ induced severe sickness in mice after intraperitoneal injection at a dose of $8 \mathrm{mg} /$ $\mathrm{kg} /$ week. Modifying the surface of the GNPs by incorporating immunogenic peptides ameliorated their toxicity. This reduction in the toxicity is associated with an increase in the ability to induce antibody response.

Literature data on GNP effects on immune system are limited and contradictory. It is known that intraperitoneal injection of GNPs increases the phagocytic activity of macrophages and lymphocytes which causes their accumulation in the reticulum cells of lymphoid tissue and determines the immunomodulatory effect of GNPs. ${ }^{13}$ In other works, it was shown that GNPs may induce either pro-inflammatory ${ }^{14}$ or anti-inflammatory effects, ${ }^{15,16}$ depending on their size,${ }^{11}$ conjugation and hydrophobicity. ${ }^{17}$

In our study, the morphological changes in the spleen were presented in the form of circulatory disorders, which were characterized by insufficient blood supply with varying degrees of severity. In addition, in the spleen proliferative activation processes were found, which is consistent with data of Małaczewska. $^{25}$ After $15 \mathrm{~nm}$ and $50 \mathrm{~nm}$ GNPs administration the sizes of spleen follicles were increased due to the appearance of germinal centers, which can be explained by immune response to antigenic stimulation. ${ }^{26,27}$

The analysis of morphological alterations in blood cells and bone marrow indicators showed that more pronounced changes were observed in leukocyte number at $15 \mathrm{~nm}$ and $50 \mathrm{~nm}$-GNP administration. The changes in leukocyte ratio in the bone marrow and stimulation of the granulocytic lineage of hematopoiesis are probably related to the decrease in the number of leukocytes in peripheral blood after $15 \mathrm{~nm}$ and $50 \mathrm{~nm}$ GNP administration. These results are consistent with the work of Zhang et al. Eleven where the size-dependent GNP biodistribution in the blood and bone marrow cells was noted at intraperitoneal injection and $5 \mathrm{~nm}$ and $30 \mathrm{~nm}$ particles induced a decrease of WBC population.

According to our results, the signs of strengthening of the processes of cell proliferation and differentiation of lymphoid cells in lymph nodes were revealed after 15 day administration of GNPs. This is confirmed by the increase of number of cells with mitotic figures, which was manifested in various degrees in different areas of lymph nodes. The number of small lymphocytes and immunoblasts in zone of lymphoid follicles and paracortical area was increased. Thus, the dynamics of different forms of lymphocytes in structural zones of the lymph nodes was the morphological evidence of activation of the proliferation and differentiation of immune cells.

Our results agree with the data of other studies which found that the immune response to GNPs may therefore be tissue dependent, as well as particle size-dependent, ${ }^{28}$ and future studies should be expanded upon these findings.

\section{Conclusion}

In this work, we have studied the basic hematological parameters and morphological changes in lymphatic organs after a prolonged oral administration of different sized GNPs. The main idea behind the present study was to evaluate the possible immunostimulation or immunotoxical effects in terms of alterations noticed in lymphoid organs and blood of animals exposed to GNPs of different size. To the end, 2, 15 and $50 \mathrm{~nm}$ GNPs were administered for $1 \mathrm{~mL}$ of GNPs once a day for 15 days at a dosage of $190 \mu \mathrm{g} / \mathrm{kg}$ of body weight. The main results of the study are as follows.

The main results of the study are as follows. In peripheral blood, we observed the size-dependent dynamics manifested as a reduction of the number of WBCs, lymphocytes for both, 15 and $50 \mathrm{~nm}$ GNPs and in number of monocytes for $50 \mathrm{~nm}$ GNPs. The morphological examination of the bone marrow indicated stimulation of myelocytic germ of hematopoiesis under $15 \mathrm{~nm}$ and $50 \mathrm{~nm}$ GNP administration. Specifically, we have recorded statistically significant increase in neutrophil metamyelocytes and neutrophil stab leukocytes for all GNP sizes and in neutrophil myelocytes for 15 and $50 \mathrm{~nm}$ GNPs. Finally, in the lymph nodes, the signs of strengthening of the processes of proliferation and differentiation of cellular elements were revealed, that could be related to the presence of immunomodulation effect of $15 \mathrm{~nm}$ and $50 \mathrm{~nm}$ GNPs, especially for the immune cells of the lymph nodes. In particular, for 15 and $50 \mathrm{~nm}$ GNPs, statistically significant increase in the number of cells per area of $6400 \mu \mathrm{m}^{2}$ has been observed for small and middle lymphocytes, immunoblasts and mitotic figures in lymph follicles, as well as in small lymphocytes in paracortical zones.

To summarize, further studies are needed to follow the GNP-mediated the innate (phagocytosis, 
cytokine response, complement activity, etc.) and adaptive immune responses such as specific antibody secretion, cytotoxic effect, cytokine synthesis etc. Further, the morphological changes in peripheral blood and lymphoid nodes under prolonged exposure to GNPs and the time-dependent reversibility of those changes seem to be desired additional studies. We plan to investigate these issues in future studies. Some parts of this plan are under way.

\section{Acknowledgments}

The experimental work and morphological studies done by ABB, SSP, OVZ, GNM, OVM, IOB and NAN was conducted by the state task of Russian ministry of Health. The work done by BNK, VAB and NGK on design and production nanoparticles was supported by grant No. 14-13-01167 of the Russian Science Foundation, the work done by VVT on interpretation of experimental data was supported by grant No. 14-15-00186 of the Russian Science Foundation.

\section{References}

1. G. Oberdorster, E. Oberdorster, J. Oberdorster, "Nanotoxicology: An emerging discipline evolving from studies of ultrafine particles," Environ. Health. Perspect. 113, 823-839 (2005).

2. W. R. Chen, X. Li, M. F. Naylor, H. Liu, R. E. Nordquist, Advances in Cancer Photothermal Therapy, in Handbook of Photonics for Biomedical Science, V. V. Tuchin, Ed., Boca Raton, pp. 499526, CRC Press (2010).

3. S. E. McNeil, "Nanotechnology for the biologist," Leukoc. Biol. 78, 585-594 (2005).

4. J. F. Hillyer, R. M. Albrecht, "Gastrointestinal persorption and tissue distribution of differently sized colloidal gold nanoparticles," Pharm Sci. 90, 1927-1936 (2001).

5. G. S. Terentyuk, G. N. Maslyakova, L. V. Suleymanova, B. N. Khlebtsov, B. Y. Kogan, G. G. Akchurin, A. V. Shantrocha, I. L. Maksimova, N. G. Khlebtsov, V. V. Tuchin, "Circulation and distribution of gold nanoparticles and induced alterations of tissue morphology at intravenous particle delivery," J. Biophoton. 2, 292-302 (2009).

6. J. F. Hillyer, R. M. Albrecht, "Correlative instrumental neutron activation analysis, light microscopy, transmission electron microscopy and X-ray microanalysis for qualitative and quantitative detection of colloidal gold Spheres in biological specimens," Microsc. Microanal. 4, 481-490 (1998).

7. W. H. De Jong, W. I. Hagens, P. Krystek, M. C. Burger, A. J. Sips, R. E. Geertsma, "Particle sizedependent organ distribution of gold nanoparticles after intravenous administration," Biomaterials $\mathbf{2 9}$, 1912-1919 (2008).

8. X.-D. Zhang, H.-Y. Wu, D. Wu, Y.-Y. Wang, J. H. Chang, Z.-B. Zhai, A.-M. Meng, P.-X. Liu, L.-A. Zhang, F.-Y. Fan, "Toxicologic effects of gold nanoparticles in vivo by different administration routes," Int. J. Nanomed. 5, 771-777 (2010).

9. J. P. M. Almeida, A. L. Chen, A. Foster, R. Drezek, "In vivo biodistribution of nanoparticles," Nanomedicine 6, 815 (2011).

10. Y.-S. Chen, Y.-C. Hung, I. Liau, G. S. Huang, "Assessment of the in vivo toxicity of gold nanoparticles," Nanoscale Res. Lett. 4, 858-864 (2009).

11. X.-D. Zhang, D. Wu, X. Shen, P.-X. Liu, N. Yang, B. Zhao, H. Zhang, Y.-M. Sun, L.-A. Zhang, F.-Y. Fan, "Size-dependent in vivo toxicity of PEG-coated gold nanoparticles," Int. J. Nanomed. 6, 2071-2081 (2011).

12. G. Pacheco, "Studies on the action of metallic colloids on immunisation," Mem. Inst. Oswaldo Cruz 18, 119-149 (1925).

13. S. A. Staroverov, N. M. Aksinenko, K. P. Gabalov, O. A. Vasilenko, I. V. Vidyasheva, S. Yu. Shchyogolev, L. A. Dykman, "Effect of gold nanoparticles on the respirator activity of peritoneal macrophages," Gold Bull 42(2), 153-156 (2009).

14. H. J. Yen, S. H. Hsu, C. L. Tsai, "Cytotoxicity and immunological response of gold and silver nanoparticles of different sizes," Small 5, 1553-1561 (2009).

15. C. L. Villiers, H. Freitas, R. Couderc, M. B. Villiers, P. N. Marche "Analysis of the toxicity of gold nano particles on the immune system: effect on dendritic cell functions," J. Nanopart. Res. 12, 55-60 (2010).

16. C. Y. Tsai, S. L. Lu, C. W. Hu, C. S. Yeh, G. B. Lee et al., "Size-dependent attenuation of TLR9 signaling by gold nanoparticles in macrophages," Immunology 188, 68-76 (2012).

17. D. F. Moyano, M. Goldsmith, D. J. Solfiell, D. Landesman-Milo, O. R. Miranda et al., "Nanoparticle hydrophobicity dictates immune response," J. Am. Chem. Soc. 134, 3965-3967 (2012).

18. V. V. Sumbayev, I. M. Yasinska, C. P. Garcia, D. Gilliland, G. S. Lall, B. F. Gibbs, D. R. Bonsall, L. Varani, F. Rossi, L. Calzolai, "Gold nanoparticles downregulate interleukin-1 $\beta$-induced pro-inflammatory responses," Small 9, 472-477 (2013).

19. N. G. Bastús, E. Sánchez-Tilló, S. Pujals, C. Farrera, M. J. Kogan, E. Giralt, A. Celada, J. Lloberas, V. Puntes, "Peptides conjugated to gold nanoparticles 
induce macrophage activation," Mol. Immunol. 46, 743-748 (2009).

20. L. A. Dykman, V. A. Bogatyrev, "Gold nanoparticles: Preparation, functionalisation and applications in biochemistry and immunochemistry," Russ. Chem. Rev. 76, 181-194 (2007).

21. G. Frens, "Controlled nucleation for the regulation of the particle size in monodisperse gold suspensions," Nat. Phys. Sci. 241, 20-22 (1973).

22. D. G. Duff, A. Baiker, P. P. Edwards, "A new hydrosol of gold clusters. 1. Formation and particle size variation," Langmuir 9, 2301-2309 (1993).

23. G. A. Merkulov, "Course of Pathological/Histological Technique," (in Russian), Meitsina, Leningrad (1969).

24. P. V. Turner, T. Brabb, C. Pekow, M. A. Vasbinder, "Administration of substances to laboratory animals: routes of administration and factors to consider," J. Am. Assoc. Lab. Anim. Sci. 50, 600613 (2011).

25. J. Małaczewska, "The in vitro effect of commercially available noble metal nanocolloids on the splenocyte proliferative response and cytokine production in mice," Pol. J. Vet. Sci. 17, 37-45 (2014).

26. J. P. M. Almeida, A. Y. Lin, R. J. Langsner, P. Eckels, A. E. Foster, R. A. Drezek, "In vivo immune cell distribution of gold nanoparticles in naïve and tumor bearing mice," Small 10, 812-819 (2014).

27. H. Chen, A. Dorrigan, S. Saad, D. J. Hare, M. B. Cortie, S. M. Valenzuela, In vivo study of spherical gold nanoparticles: inflammatory effects and distribution in mice," PLoS ONE 8, e58208 (2013).

28. J. P. Almeida, E. R. Figueroa, R. A. Drezek, "Gold nanoparticle mediated cancer immunotherapy," Nanomedicine 10, 503-514 (2014). 